\title{
REVELANDO E COMPREENDENDO O RELACIONAMENTO PROFESSOR-ALUNO EM
}

MARKETING

\section{REVEALING AND UNDERSTANDING PROFESSOR-STUDENT RELATIONSHIP IN MARKETING}

\section{ANA AKEMI IKEDA}

Professora Doutora e Livre-Docente em Marketing da Faculdade de Economia, Administração e Contabilidade da Universidade Federal de São Paulo (FEA-USP). Rua Engenheiro Bianor, 79, ap. 22, Butantã - São Paulo - SP - CEP 05508-900 E-mail: anaikeda@usp.br

\section{FÁTIMA CRISTINA TRINDADE BACELLAR}

Professora Doutora em Marketing pela Faculdade de Economia, Administração e Contabilidade da Universidade Federal de São Paulo (FEA-USP). Professora de Marketing do IBMEC/RJ. Avenida Divino Salvador, 166, Moema - São Paulo - SP - CEP 20030-020 E-mail: timacris@uol.com.br 


\section{RESUMO}

Os desafios do magistério são grandes e numerosos apresentando pressões com origens diversas. O objetivo do presente trabalho, de caráter exploratório e natureza qualitativa, é levantar a perspectiva de professores de Marketing em relação aos alunos de diferentes níveis: graduação e pós-graduação. Foram feitas entrevistas individuais em profundidade para a coleta de dados e utilizada a grounded theory para a condução do trabalho e análise dos dados. O estudo conclui que, para os professores que dão aulas em todos os níveis, observa-se uma tendência na preferência pelos alunos de mestrado/doutorado seguido pela graduação e uma reação em geral negativa em relação à forma como a avaliação dos professores é feita e apresentada aos alunos, ainda que como prática seja aprovada pelos entrevistados. Por fim, sugere-se, com base nos relatos dos entrevistados, a implementação da filosofia e dos conceitos de Marketing em sala de aula.

\section{PALA VRAS-CHAVE}

Marketing; Professores; Alunos; Aprendizagem; Teoria fundamentada.

\section{ABSTRACT}

Teaching profession challenges are huge and plentiful bringing pressure came from many sources. The aim of this study, exploratory and qualitative, is to raise the perspective of Marketing professors regarding the way they face their students at different levels: undergraduate and graduated students. The method of data collection was individual in-depth interviews and the method for works conduction and data analysis was the grounded theory. The study concludes that those who teach to all levels tend to prefer master/doctoral students followed by students of college level. At the same time, there is a negative reaction to the way professor evaluations are made and presented to students, although the practice itself is approved by the interviewees. Finally, grounded from interviewees' reports, the implementation of Marketing philosophy and concepts into the classroom is suggested. 


\section{KEYWORDS}

Marketing; Professors; Students; Learning; Grounded theory.

\section{INTRODUÇÃO}

Atualmente, os professores de ensino superior sofrem diversas pressões. Os desafios do magistério são grandes e numerosos. Ser um professor universitário de Marketing traz ainda outras pressões com origens diversas. E, atualmente, não faltam desafios. Um dos mais evidentes e constantes é a pressão pela qualidade de ensino. Por exemplo, o modelo de ensino tradicional, baseado em leituras prévias e aulas expositivas, tem sido criticado por ser um processo passivo de transmissão de conhecimento de forma que esse modelo tradicional está sendo complementado e auxiliado pela tecnologia, provocando uma busca por algum tipo de treinamento ou ajuda por parte de professores para alcançar o passo desses novos instrumentos agora disponíveis (FERRELL, I995, p. 2).

Além da pressão para acompanhar o ritmo das mudanças, existe uma outra para que os professores se posicionem mais próximos de seus alunos, aumentando sua motivação e interesse pelas aulas e melhorando a aprendizagem dos conceitos transmitidos (CLARK III; FLAHERTY; MOTTNER, 200I, p. I69; EMERY; KRAMER; TIAN, 200I, p. IIO; DESAI; DAMEWOOD; JONES, 200I). Por outro lado, ao procurar ser criativo, o medo de errar, de que seus métodos não funcionem ou de que venha a ser mal compreendido e, conseqüentemente, mal-avaliado, se junta ao trabalho adicional inerente de atividades inovadoras e, como ressaltam AlbersMiller, Straugham, Prenshaw (200I, p. 249), à falta de recompensas e de suporte por parte das instituições. Contudo, a prática generalizada de aplicar questionários de avaliação a cada aula ou a cada curso acaba se transformando em armas contra a criatividade, conforme ressalta Armstrong (I998). Ou seja, é importante refletir sobre as recompensas e os riscos, para o professor, por ser inovador e como gerar e manter um ambiente propício para a criatividade e a inovação.

Também deve ser ressaltado que Marketing pode ser ensinado em diferentes níveis tanto para alunos de graduação como de pós-graduação, inclusive de cursos de especialização, ou como são mais conhecidos no Brasil de MBAs em Marketing e mesmo para indivíduos fora do sistema formal de ensino e que, por exemplo, buscam ajuda para a solução de problemas de suas empresas. Obviamente, esses públicos apresentam algumas semelhanças, assim como grandes e significativas diferenças entre si. Todavia, deve ser ressaltado que esse estudo não enfoca a visão do aluno, qualquer que seja seu nível, mas sim a visão do professor em relação a seus alunos. 


\section{PROBLeMA DE PESQUISA E OBJETIVOS}

Uma forma de contribuir para o desenvolvimento da atividade de ensino de Marketing é por meio de pesquisas sobre as práticas educacionais, levantando, entre outros aspectos, o relacionamento professor-aluno e, mais especificamente, a forma como os professores encaram esse público. O objeto de estudo do presente trabalho é o ensino de Marketing e os sujeitos são os professores de Marketing. A pergunta de pesquisa que este estudo pretende responder poderia ser resumida da seguinte forma: "Como os professores de Marketing encaram seus alunos e que diferenças percebem entre os diferentes níveis?”.

Ou seja, o objetivo fundamental é entender a visão dos professores de Marketing em relação a seus alunos e, por conseguinte, como se relacionam com eles.

\section{REVISÃO BIBLIOGRÁFICA}

A forma como os professores vêem os alunos influenciará a forma como lidarão com eles. Para Zabalza (2002, p. 209), "a tendência de rotular os estudantes de acordo com critérios irregulares está bastante arraigada em nossa cultura profissional". Ou seja, o autor sugere que os professores já têm de antemão uma tendência a tecer preconceitos em relação aos alunos. O termo preconceito não se refere exclusivamente a algo negativo, apenas como algo prévio, que foi formado antes do contato ou conhecimento apurado da realidade. Masetto (2003, p. 35) revela um primeiro preconceito comum na maneira em que os professores encaram os alunos:

É evidente que o que prevalece na atuação docente é um processo de ensino no qual o professor 'ensina' aos alunos que 'não sabem'; e estes reproduzem as informações recebidas nas provas ou nos exames buscando sua aprovação.

Uma mudança na percepção do professor em relação a seus alunos, por exemplo, passando a considerá-los como "adultos que podem se co-responsabilizar por seu período de formação profissional” (MASETTO, 2003, p. 30) pode ter muitos desdobramentos. Zabalza (2002, p. 202) enfatiza que o apoio dado pelo professor ao aluno é um aspecto crucial do processo de ensino-aprendizagem. A busca da quantidade ideal de apoio a ser oferecido é um desafio para o docente: "nunca oferecer mais ou menos ajuda que a necessária" (ZABALZA, 2002, p. 202). Ou seja, buscar desenvolver a autonomia dos alunos, mas não deixá-los abandonados à própria sorte sob o risco de que eles se limitem a copiar o que encontram nos livros ou na Internet. 
Por outro lado, o conhecimento e a compreensão de como os alunos aprendem também são fundamentais. Com relação a esse aspecto, a contribuição de Zabalza (2002) é bem interessante. Para o autor, os estudantes universitários podem apresentar quatro diferentes estratégias de aprendizagem: I. superficial - sem reflexão sobre o objetivo a ser alcançado, o objetivo é ter um bom desempenho na prova ou completar a tarefa com o menor esforço possível; 2. profundo - dedicação à tarefa utilizando capacidades cognitivas de alto nível, no final atribuição de uma certa lógica pessoal ao que aprende; 3. estratégico - intenção de obter o máximo de rendimento pelo valor extrínseco à tarefa, o aluno fará tudo para obter uma boa classificação; e 4. patológico - envolvimento de sentimentos e atitudes negativas em relação à aprendizagem que acaba por ser tornar uma forma de estresse.

Em consonância com isso, Masetto (2003, p. 23) afirma que, ainda que de forma iniciante, um razoável número de docentes vem se preocupando em chamar o aluno para se envolver com a matéria que está sendo estudada. Obviamente, a grande responsabilidade desse processo recai sobre os ombros do professor, mas Moreira (I997, p. 72) ressalta que os alunos também têm um papel preponderante, inclusive na geração de um ambiente mais propício para a aprendizagem.

Aspecto particularmente importante é a questão da avaliação de professores, comum em escolas de Administração (MECENAS, 2002; KRUGLIANSKAS; VASCONCELLOS, 2002). Para Pimenta e Anastasiou (2002, p. III), a contribuição dos alunos é importante no processo de desenvolvimento profissional de seus professores, "pois nos fazem ouvir sua voz em instrumentos de avaliação institucional. Por mais questionáveis que sejam [...] servem de referência para a análise da instituição e da ação docente da perspectiva do alunado".

Para Moreira (I997, p. 67), "os alunos são, via de regra, conscientes de que cada professor conduz o curso dentro de um estilo peculiar, muitas vezes ditado pelas próprias características da matéria". Godoy (1992, p. 77) que estudou detalhadamente a preferência dos alunos em relação às atividades dos professores sugere que eles "preferem professores que variam a forma de desenvolver suas aulas". Para Godoy (1992, p. 82), embora seja muito importante conhecer as expectativas dos alunos para poder atuar com base nelas e promover mudanças, não deve haver a visão estreita de que o ambiente de ensino deva ser organizado apenas para satisfazer as características e preferências dos aprendizes, ou seja, isso não deve ser feito com o mero objetivo de agradar os alunos.

Essa reflexão nos remete à questão do conceito de que o aluno é um cliente que paga e exige (ZABALZA, 2002, p. I87), e um ponto relevante que ainda não foi mencionado se refere ao papel das instituições de ensino em relação a essa questão. Para Moreira (I997, p. 70), os dirigentes podem desequilibrar a estabilidade política a favor dos alunos, principalmente quando premidos por considerações de demanda e oferta, tão comuns no ensino particular. Nesse processo, o 
professor vai pouco a pouco perdendo posições e se tornando vulnerável dentro da instituição. Como resultado, muitos podem passar à busca de popularidade que pode tornar-se até mais importante do que a própria qualidade de ensino.

Cunha (I994, p. 7I), em pesquisa realizada com alunos de cursos superiores em diversas áreas, observou que os estudantes não apontam como melhores professores os chamados bonzinhos. Ao contrário, segundo dados de sua pesquisa, o aluno valoriza o professor que é exigente, que cobra participação e tarefas, pois ele percebe que esta é também uma forma de interesse se articulada com a prática cotidiana da sala de aula. Cunha (I994, p. 72) também concluiu que para os alunos, o bom professor é aquele que domina o conteúdo, escolhe maneiras adequadas de apresentar a matéria e tem bom relacionamento com o grupo. Além disso, seus entrevistados demonstravam grande valor ao prazer de aprender, algo que se poderia traduzir como um clima positivo na sala de aula; de forma que o senso de humor do professor, o gosto de ensinar, o tornar a aula agradável, interessante são aspectos que os alunos apontam como fundamentais.

\subsection{O ALUNO DE MARKETING}

O ensino de Marketing abre diversas frentes no que se refere a seu públicoalvo: estudantes de graduação em Administração ou especificamente de Marketing, estudantes de graduação de outras áreas que tenham Marketing como disciplina, alunos de pós-graduação, stricto sensu ou lato sensu tipo MBA, novamente tanto na área específica de Marketing como em outras áreas que mantenham essa disciplina em seu currículo; e outros tipos de pessoas que desejem, por exemplo, abrir seu próprio negócio e necessitem conhecer um pouco mais sobre Marketing. São grupos bastante diferenciados, com características distintas e que buscam objetivos e valores diferentes, conforme apontado por Oliveira (2003).

Poucos estudos abordam especificamente estudantes de Marketing, porém um deles apresenta a visão de alunos de diferentes níveis em relação a diversos aspectos, entre eles, as características que mais valorizam em seus professores (IKEDA; VELUDO-DE-OLIVEIRA; MIYAZAKI, 2004). Os atributos do professor ideal também são ligeiramente diferentes entre os tipos de alunos, embora as qualidades ser didático, usar exemplos práticos e ter experiência de mercado sejam comuns a todos os grupos, apenas variando de posição. Outro estudo se refere aos objetivos dos alunos de um curso de MBA. Bacellar, Aguiar e Castilho (2003) realizando um levantamento com alunos de uma grande escola de Administração observaram diferentes perfis de alunos quanto à escolha de disciplinas eletivas. Entre os perfis encontraram-se aqueles que buscam efetivamente um desenvolvimento profissional e estão atentos para o que ocorre no mercado e na sua empresa e os que buscam apenas um diploma de pós-graduação sem 
maiores preocupações a não ser com o horário em que a disciplina é oferecida. A principal contribuição desse estudo é mostrar que, mesmo dentro de uma única turma de determinado nível, podem existir diferenças claras entre os objetivos e, conseqüentemente, entre os perfis dos alunos.

\section{METODOLOGIA DO ESTUDO}

O presente estudo é de caráter exploratório e de natureza qualitativa. A de coleta de dados foi por meio de entrevistas individuais em profundidade e, para a condução do trabalho e análise dos dados, utilizaram-se os procedimentos da grounded theory.

A grounded theory, concebida para o desenvolvimento de teorias, conceitos, hipóteses e proposições baseados em dados sistematicamente coletados e analisados em vez de pressupostos, outras pesquisas ou sistemas teóricos pré-existentes (TAYLOR; BOGDAN, I998, p. I37; GOULDING, 2002, p. 42), é baseada em uma série de procedimentos bem definidos que têm por objetivo assegurar que as conclusões e a teoria resultante sejam fiéis aos dados sistematicamente coletados e analisados (STRAUSS; CORBIN, I998, p. I2). Embora sua finalidade seja a construção de teorias, sua utilização não necessariamente precisa ficar restrita apenas aos pesquisadores que têm esse objetivo. Para Strauss e Corbin (I998, p. 288), "o pesquisador pode usar alguns, mas não todos os procedimentos para satisfazer seus objetivos de pesquisa”.

\subsection{PROCEDIMENTOS DA PESQUISA DE CAMPO}

Para a seleção dos entrevistados, dois aspectos são considerados: o perfil dos entrevistados e a quantidade de entrevistas. Nesse tipo de procedimento, a escolha dos respondentes deve obedecer a critérios diferentes dos normalmente associados à definição de uma amostra em uma pesquisa de natureza quantitativa. De acordo com os procedimentos característicos da grounded theory, o processo de escolha dos informantes (denominado amostragem teórica) deve ser feito, primeiro, para proporcionar o máximo de informações com a maior variabilidade possível para que seja aberto um maior número de códigos iniciais; depois, viabilizar o processo de comparação constante com as demais fontes de informação (outras entrevistas, literatura etc.) para que o pesquisador possa reunir códigos e definir categorias e conceitos; e, por fim, verificar o entendimento das categorias e apresentá-las com a teoria central desenvolvida. No presente estudo, a escolha dos entrevistados seguiu os critérios de conhecimentos pessoais das pesquisadoras e de indicação de outros professores. 
Foram entrevistados io professores de Marketing com diferentes níveis de experiência (entre I e mais de 20 anos), de ambos os sexos e representando as seguintes escolas: no Rio de Janeiro, Universidade Cândido Mendes, Instituto COPPEAD/UFRJ, EBAPE/FFV, IBMEC-RJ e UNIVERCIDADE; em São Paulo, ESPM-SP, FAAP, FECAP, IBMEC-SP, UNIP e USP. Todos os níveis de estudo (graduação, MBA e mestrado/doutorado) foram representados, embora nem todos os professores entrevistados lecionassem em todos os níveis. As entrevistas duraram entre 40 e I80 minutos e foram realizadas entre $9 / 12 / 2003 \mathrm{e}$ $7 / 12 / 2004$, resultando em aproximadamente 16 horas de gravação e pouco mais de 200 páginas transcritas.

O processo de entrevistas se iniciou com um roteiro composto de itens e perguntas elaborado com base nas referências bibliográficas, assim como nas experiências das pesquisadoras como professoras da área. À medida que as entrevistas evoluíam, o roteiro inicial ia sendo ligeiramente alterado. Esse processo de aprimoramento das perguntas também foi abordado por Strauss (I987, p. 27I-272) como algo natural e inerente ao amadurecimento do próprio pesquisador. Para Goode e Hatt (I952, p. 239), essa flexibilização "permite ao entrevistador expressar a questão de tal maneira que o informante possa entendê-la mais facilmente".

\section{QUADRO I}

FAMÍLIAS E SUBFAMÍLIAS OBTIDAS NO PRESENTE ESTUDO E A QUANTIDADE DE CÓDIGOS RELACIONADOS A CADA UMA DELAS

\begin{tabular}{llc} 
Como encara e reage à avaliação de professores & 56 \\
\cline { 2 - 3 } Como vê os alunos & Relacionamento professor-aluno & 44 \\
\cline { 2 - 3 } & Graduação & 29 \\
\cline { 2 - 3 } & Mestrado/Doutorado & 61 \\
\cline { 2 - 3 } & Outros públicos & 18 \\
\hline Dificuldades com & Dificuldade de fazer o aluno ler & 13 \\
\cline { 2 - 3 } alunos & Confrontações & 43 \\
\cline { 2 - 3 } & Gerenciamento de expectativas & 43 \\
\hline Papel do professor & & 433 \\
\hline Total & & 43 \\
\hline
\end{tabular}

Fonte: Elaborado pelas autoras. 
No processo de codificação aberta foi utilizado o software ATLAS.ti versão 5.0, obtendo-se 433 códigos especificamente relacionados com o tema Relacionamento Professor-Aluno e temas correlatos, separados em dez famílias (e respectivos códigos), conforme o Quadro I. O objetivo da separação dos códigos em famílias é facilitar o processo de análise e interpretação. A própria separação dos códigos pode ser considerada um primeiro passo no processo de interpretação.

A base teórica utilizada para a interpretação foi o Interacionismo Simbólico, o que significa observar e entender o comportamento do ponto de vista dos participantes e aprender sobre o seu mundo, sobre suas interpretações de si mesmos no contexto de determinadas interações e sobre as propriedades dinâmicas das interações (LOCKE, 200I, p. 25). Para Denzin (200I, p. II9), interpretar é "a tentativa de explicar os significados", exatamente o que se pretendeu realizar neste estudo.

\section{ANÁLISE DOS RESULTAdOS}

A visão que o professor tem dos alunos, ou seja, a maneira como os percebe, define sua interação com eles. As atitudes formadas em relação aos alunos dependem de diversos fatores: a própria visão de mundo do docente, suas crenças e valores, sua maturidade pessoal e profissional, as circunstâncias em que se encontra o nível de curso no qual leciona, o tipo de aluno com que se relaciona e até mesmo a instituição à qual está vinculado. Tendo tudo isso em mente, podese imaginar a variedade de possíveis atitudes e definições por parte dos professores e, de fato, isso foi observado. Em primeiro lugar são analisados os aspectos gerais do relacionamento professor-aluno e as dificuldades que os professores apontam nesse relacionamento. Em seguida, abordada a visão que os professores têm de seus alunos em cada nível (graduação, MBA, mestrado/doutorado e outros públicos). Por fim, discute-se um aspecto em particular dessa relação: a avaliação dos professores feita pelos alunos.

\section{a) Relacionando-se com os alunos: lado a lado ou pólos opostos?}

O gosto pelo relacionamento com os alunos é muito constante nos discursos dos professores entrevistados. Em vários casos, esse foi o aspecto apontado pelos professores como determinante para a escolha da carreira ou, pelo menos, um dos mais importantes. A questão de aprender com o aluno, também aparece constantemente nos discursos dos professores.

O relacionamento com os alunos é visto como uma parte da própria atividade de ser professor, fato que se descobre ao longo do tempo; tal situação foi recorrente neste estudo. Por exemplo, um dos professores declarou que "desco- 
briu como é a relação com os alunos" e passou a ter "grande prazer em dar aula". A questão do aprendizado com o aluno decorre de uma visão mais positiva deste: "O aluno, aliás, eu nem gosto da palavra aluno porque aluno, se você for analisar a formação, quer dizer que o cara não tem luz, a-luno, sem luz. E o cara tem muita luz. E tem muita luz que a gente pode trocar".

A possibilidade de aprender com os estudantes pode ser vista como real não apenas no cotidiano de sala de aula, mas também no momento da correção dos trabalhos de fim de curso. Aprender com os alunos também pode significar aproveitar suas experiências até mesmo na construção das aulas.

A convivência fora da sala de aula também foi abordada em alguns casos, como, por exemplo, alguns professores que fazem questão de participar de eventos sociais promovidos pelos alunos.

Embora em geral predomine uma visão positiva dos estudantes, nem todos os professores demonstraram uma atitude tão aberta para com eles. O receio em estabelecer um relacionamento mais próximo pode se revelar até mesmo como uma forma de defesa.

Em relação às dificuldades encontradas no relacionamento com os alunos, uma das mais freqüentes envolve a questão da leitura dos materiais. Ter dificuldade para fazer com que os alunos leiam foi uma unanimidade, o que variou foi a maneira como cada professor encara isso e procura resolver o problema. Alguns se cobram a descoberta de um meio de melhorar essa questão, outros procuram se adaptar ao fato buscando no aluno uma solução, e outros simplesmente têm isso como dado, se ressentem e desistem de tentar fazer algo, frustrando-se e até certo ponto desprezando os alunos.

Uma dificuldade mais sensível é a confrontação, quando o professor se sente desafiado pelo estudante e incomoda-se com isso:

Então vem cá, você sabe a prática mesmo? Então o aluno ele [...] ele te [...] ele tá tentando te checar o tempo todo. Ele é desconfiado em relação ao seu conhecimento, né. E [...] é uma coisa complicada isso para o professor de Marketing [...].

Admite-se que esse tipo de confrontação pode "derrubar uma aula". Para evitar esse tipo de questionamento, o professor pode usar diferentes estratégias. Uma delas é "entrar forte" em sala de aula, ou seja, demonstrar autoridade. Outra estratégia é o oposto, ou seja, simplesmente admitir que não é o dono da verdade e deixar isso claro para os alunos: "[...] o professor de Marketing, à medida que ele vai ganhando mais experiência, ele vai se saindo melhor das situações para dizer: não, olha, sobre isso eu te envio um artigo. Você quer que eu te envie?”.

De qualquer maneira, essa é uma fonte de grande desgaste para o professor. Embora até aqui encarado de forma geral, o relacionamento professor-aluno 
assim como as dificuldades encontradas ganham tonalidades diferentes conforme o nível do estudante. $\mathrm{O}$ item a seguir analisa como os professores encaram cada nível individualmente.

b) Alunos de graduação: tábulas rasas, em busca do diploma ou simplesmente uma nova geração a ser compreendida?

Começando pelos alunos da graduação, a visão que os professores têm deles varia bastante, e essa variação está ligada em parte ao tipo de instituição em que o professor trabalha; ela determinará o perfil dos alunos na sala de aula. Assim, estudantes mais jovens e, conseqüentemente menos experientes, podem ser vistos como verdadeiras tábulas rasas. Esses alunos devem ser moldados e preenchidos com conteúdo para prepará-los para suas experiências vindouras. A inexperiência nos alunos, por parte dos professores, pode ser encarada como uma oportunidade e fonte de motivação para seduzi-lo para o estudo do Marketing. A cobrança e a atenção constante dos professores se mostram mais necessárias quando se ensina para esse público. Dar aula na graduação pode ser visto como o grande desafio do professor, onde ele efetivamente exerce sua docência.

Contudo, o entusiasmo nem sempre é compartilhado por todos e a percepção de que o aluno é inexperiente pode ter um efeito desmotivador: "A graduação é muito básico, vai discutir básico, não adianta discutir nada mais profundo com eles porque eles não vão pegar mesmo. Eu acho meio boring, é meio, sei lá [...]”.

Do ponto de vista de alguns professores, os alunos mais novos podem estar interessados apenas em passar, obter seu diploma; fato causado pela falta de perspectivas que esse aluno tem em relação ao mercado de trabalho. Outro grande problema é reter a atenção desse estudante, fazê-lo prestar atenção na aula sem dispersar, sem conversar com os colegas. O próprio professor pode assumir uma parcela de culpa, pois dependendo de como aborda sua aula, pode gerar mais ou menos atenção. O contraste dos relatos a seguir deixa claro que a atuação em sala de aula em seu sentido mais abrangente é fundamental para a retenção da atenção dos alunos:

o que não funciona, ou seja, simplesmente ler uma transparência (uma aula burocrática), contra o que funciona, ou seja, envolver os alunos contando piadas, sendo engraçado ou procurar o que interessa o aluno para despertar sua curiosidade e, conseqüentemente, manter sua atenção.

Por fim, os alunos de graduação podem ser encarados como um produto em contraste com a visão do aluno como cliente: "Aluno não é cliente, meu aluno não é cliente. Meu aluno é produto". 
Essa visão não é necessariamente negativa, ao contrário, o aluno pode ser encarado como o principal produto de uma instituição: "eu digo pras pessoas que têm que contatar esse pessoal aqui, o que eu digo para eles é o seguinte, o melhor produto da casa são os alunos que a gente tem".

\section{c) Alunos de MBA: os grandes confrontadores dos professores?}

A visão que os professores têm em relação aos alunos de MBA é bem diferente dos da graduação. Em geral, a definição de um curso de MBA gira em torno da apresentação de técnicas para serem aplicadas no dia-a-dia dos alunos executivos: "O que é um MBA ou um curso para executivos, in-company ou especialização? É a apresentação de técnicas aplicadas na prática de uma forma mais imediata".

Seu papel como docente também é visto de forma bem distinta. Para atuar como professor de um curso de MBA, o professor tem que estar preparado, se ele "tiver o conhecimento prático, ele pode dar uma aula para executivos". O nível de confrontação dos alunos é visto como maior, alguns professores acreditam que o aluno de MBA está sempre disposto a "medir forças com o professor". Um dos professores entrevistados teve a experiência de ter sido aluno de MBA e reforça esse ponto de vista por sua própria experiência pessoal:

O que ficou bem claro quando eu relembrei o meu tempo de MBA que realmente muitas vezes a gente tá lá pra discutir com o professor, medir força ou pra simplesmente tirar o diploma.

Um agravante no relacionamento é o fato desse ser o aluno que mais percebe a si mesmo como cliente, um cliente que paga muitas vezes caro e, por isso, exige: "E além do que eu não recebo nada para estudar, eu tenho que pagar ainda por cima. Então, o cara tem que fazer o que eu quero".

Para os professores, ensinar para esses alunos significa fazê-los reavaliar suas práticas em função do que se pode extrair da teoria. Um dos grandes problemas apontado por muitos professores é o fato desse tipo de aluno ser reticente quanto a aspectos teóricos, se apegando demasiadamente à sua prática de trabalho. Segundo alguns professores, parte da responsabilidade dessa rejeição se deve às escolas: "E pior, esse comportamento é até reforçado pelas próprias coordenações de curso que dizem, 'ah, aqui vocês vêm aprender com os executivos de mercado'. Isso desvaloriza a teoria”.

Rejeitando a teoria, o que parece resultar para os professores é a expectativa do fornecimento de fórmulas mágicas e eles se ressentem disso. Além do que, há o fato de ter de envolver o aluno, em geral um executivo de empresas que tem uma série de compromissos profissionais e faz seu curso à noite ou nos fins de semana. Dar aula para um MBA parece não ser tarefa fácil para os professores. $\mathrm{O}$ 
perfil é complicado para vários entrevistados. Quando se lembram de sua própria história, aqueles que também já foram executivos se identificam e sentem conseguir entendê-los melhor: "Eu sei o que os caras tão passando lá no dia-a-dia, eu conheço esse lado".

Um último aspecto é a tendência de achar que a teoria na prática é outra e, por isso, esses alunos tendem a ver a realidade de sua empresa como única e especial, impossível, portanto, de ser explicada por uma teoria genérica.

\section{d) Alunos de mestrado/doutorado: agora a história é outra}

Os alunos de mestrado/doutorado parecem ser os preferidos da maioria dos professores que já tiveram a experiência de dar aula para todos os diferentes níveis. A comparação com os alunos de MBA é inevitável.

Três aspectos sugerem que, para vários professores, dar aulas em mestrado ou doutorado significa compartilhar conhecimento. Em primeiro lugar, o uso do método de seminários muito mais difundido nesse nível que nos demais: "No Mestrado, eu dou muito seminário, os alunos estudam, eles chegam, eles apresentam".

Em segundo lugar, a grande valorização em relação ao processo de orientação: "Que, para mim, é uma das atividades que eu mais valorizo, a orientação de dissertação etc. e que passa também pela sala de aula, eu acho”.

O terceiro aspecto é o próprio objetivo de um curso de mestrado ou de doutorado: a discussão da teoria. Em geral, isso agrada muito o professor: "E no mestrado, não. No mestrado o cara tá querendo se aprofundar na teoria, como é que aquilo funciona, a teoria. Não fica tão preocupado com os exemplos".

Além disso, em geral, são turmas menores, o que possibilita um contato maior entre alunos e professores. $\mathrm{O}$ resultado é que as discussões são percebidas como mais ricas e interessantes para os professores que conseguem explorar ao máximo seu próprio potencial, assim como o de seus alunos.

\section{e) A avaliação dos professores pelos alunos: opiniões divergentes}

A última parte do relacionamento com os alunos a ser tratada refere-se à avaliação dos professores feita pelos alunos. Essa é uma prática bastante comum e disseminada em todas as escolas representadas pelos professores entrevistados.

A maior parte das reações observadas expressou sensações e atitudes negativas em relação à avaliação. Alguns a reconhecem como uma atividade válida e tiram algum tipo de retorno positivo: "Olha, eu acho fundamental a avaliação. E [...] eu costumo aproveitar muito os comentários que os alunos fazem. Dificilmente eu discordo dos alunos [...]".

No entanto, em geral, ela é vista pelos professores como um instrumento de vingança do aluno que podem distorcer a realidade e que são mal formuladas e 
mal-aplicadas: "O professor que é rígido, que cobra, que exige, e tal, que em tese está dando uma melhor aula, às vezes é mal-avaliado”.

Passar pelo crivo do aluno traz angústia para o professor porque o incomoda muito receber uma avaliação negativa da turma. Uma das razões apontadas para essa angústia é a sensação de que a apreciação não necessariamente mede a capacidade do docente, mas outros fatores vistos como menores como a simpatia provocada por ele na turma:

[...] se você for investigar o que o aluno tá respondendo, não tem nada a ver com a avaliação do professor ou do conteúdo do curso, tem a ver com a simpatia que ele teve com o professor, se ele gosta da matéria ou não. Então, isso é tudo distorcido.

Por outro lado, a impressão que os professores têm é que, para as escolas, esse é um instrumento usado para definir sua permanência em seus quadros. O resultado é que muitos vêem como forma de obter boas avaliações passar a ter um comportamento mais permissivo, menos exigente para com os alunos: "Faz um curso que conta muita piada, é amigo de todo mundo, dá dez pra todo mundo, tua avaliação vai lá na lua".

\section{f) Enxergando os alunos como interlocutores e implementando a filosofia e os conceitos de Marketing em sala de aula}

Um dos entrevistados revelou uma grande mudança ocorrida quando ele se deu conta de que estava preparando suas aulas para si mesmo e não para os alunos; suas palavras definem bem seus sentimentos a respeito:

Aí descobri como é que é a relação com os alunos, parei de dar aula para um ponto indefinido no fundo da sala, comecei a olhar as pessoas nos olhos e descobri grande prazer em dar aula. [...] Quando você não tem essa referência do outro, você se prepara muito, você prepara os Power Points, as imagens, os textos e tal, as estratégias que você vai usar, mas quando você não percebe que tem um conjunto de interlocutores ali na frente de quem pode se beneficiar, aí você vai dar aula para um ponto no fundo da parede.

Essa descoberta dos alunos como interlocutores e o papel de trocar experiências com eles não necessariamente precisam acontecer depois de muitos anos de carreira. Outros professores, com experiência ainda relativamente curta, também já descobriram esse lado da docência. A aplicação do conceito de Marketing na condução de um curso implica colocar o aluno no centro do processo, procurar entendê-lo e fornecer o que necessita, ou seja, os conhecimentos relacionados à 
disciplina. Essa estratégia é utilizada por alguns dos professores entrevistados de um modo mais ou menos consciente. Por exemplo, uma estratégia é gerenciar expectativas, um conceito muito usado em Marketing de Serviços.

A forma de encarar o ensino de Marketing, usando sua conceituação aplicada à sala de aula, não deve ser vista da mesma maneira que o discurso padronizado do aluno como cliente. Pelo menos não no sentido de dar mecânica e impensadamente tudo o que o aluno deseja para conquistá-lo como cliente. Essa pode ser uma visão superficial e enganosa. Por exemplo, a relação de clientela existe e pode ser recíproca: “[...] evidentemente tem horas de clientela, tem relações de clientela o tempo todo. Tem momentos em que eu sou cliente deles, tem momentos que eles são meus clientes".

Nem se deve ter a ingenuidade nem a pretensão de atingir todos os alunos, a unanimidade é muito difícil, mas atingir uma boa parcela dentro de uma turma pode ser o ideal do professor.

A questão do relacionamento de longo prazo também encontra um paralelo na relação professor-aluno. Várias vezes foi declarado pelos professores entrevistados que um fator determinante da qualidade de seu trabalho é o fato de os alunos ainda se lembrarem, anos mais tarde, de suas aulas e ensinamentos, alguns até sendo influenciados na escolha de suas carreiras.

Então, eu acho que uma [...] uma coisa que mede a efetividade do professor é [...] que o aluno que depois de dois anos, três anos de terminado o curso, ele lembra, não do professor fisicamente, mas que ele lembra da matéria, que essa matéria de alguma forma foi útil e ele aprendeu. Então, eu acho que [...] isso é [...] é [...] é uma forma de medir a efetividade.

Por fim, usar o próprio conceito de Marketing em sala de aula, ou seja, não apenas ensinar como atrair e manter clientes satisfeitos, mas aplicá-los na prática docente, pode ser a chave para uma maior satisfação de ambas as partes, alunos e professores e, nesse sentido, ao perceberem isso os professores de Marketing seriam privilegiados em relação aos de outras áreas porque conhecem a fundo essa teoria já que a ensinam a seus alunos:

Eu acho que os professores de Marketing mais do que os de matemática financeira estão a um passo de perceber isso. Basta um empurrão. Porque eles já leram muito, já estudaram muito, já prepararam muito material. Eu acho que eles tão bem mesmo, que ainda não estejam implementando porque eles tão muito próximos de sacar. A ficha deles tá na beirinha, quase caindo, mas muitos deles não tiveram essa oportunidade. 


\section{CONSIDERAÇÕES FINAIS}

Com o objetivo de levantar a perspectiva de professores de Marketing em relação à maneira como encaram seus alunos de diferentes níveis, observouse que a maioria dos professores entrevistados expressou grande apreço pelo contato com seus alunos, inclusive fora de sala de aula. Além disso, vários dos entrevistados se mostraram preocupados em estabelecer laços de longo prazo com os alunos, tendo inclusive influenciado em decisões profissionais e na escotha de suas carreiras. Isso parece agradar bastante os professores que se sentem realizados e alguns até emocionados quando se dão conta desse seu papel. Em conformidade com Zabalza (2002, p. IIO), conclui-se que o papel tradicional do professor de transmissor de conhecimentos está sendo paulatinamente substituído pelo de facilitador da aprendizagem, ainda que nenhum dos entrevistados tenha usado esse termo especificamente.

Ainda sobre o relacionamento professor-aluno, um aspecto em especial é a questão de os professores considerarem ou não os alunos como clientes. Vários autores se mostraram radicalmente contra essa visão (FRANZ, I998; SCRABEC, 2000), assim como vários entrevistados manifestaram não concordar plenamente com essa abordagem. No entanto, é interessante relembrar a contribuição de Godoy (I992, p. 82), quando estudou as preferências de aprendizagem de alunos de graduação, de que não se trata de querer agradar os alunos, mas sim levar em consideração suas preferências ao preparar e conduzir a aula para melhor atingi-los. Nesse aspecto, os próprios conhecimentos de Marketing poderiam ser aplicados em benefício de ambas as partes.

Por outro lado, a questão do gerenciamento das expectativas se mostra bastante relevante. Conforme sugerem Zabalza (2002) e Masetto (2003), professores, como todas as pessoas, carregam preconceitos em relação a seus alunos e isso ficou claro em vários relatos. Esses preconceitos geram expectativas do professor em relação a seus alunos e, muitas vezes, barreiras de proteção são levantadas por eles. Isso é mais evidente no relacionamento com alunos de MBA, vistos por muitos como grandes confrontadores. Entender que esses alunos, assim como todos os demais, têm objetivos diferentes (BACELLAR; AGUIAR; CASTILHO, 2003) pode contribuir muito para o desenvolvimento de um relacionamento mais amigável, ao menos com aqueles que demonstram objetivos genuínos de aprendizagem. Essa questão foi abordada por diversos professores entrevistados que passam a direcionar sua atenção a esses indivíduos.

Quanto à avaliação de professores, todos os entrevistados se mostraram preocupados com a forma como ela é feita, questionando seus resultados e, algumas vezes, se ressentindo com eles. Sobretudo aqueles ligados a escolas priva- 
das mostraram claramente estar de acordo com as preocupações de Armstrong (I998) no que se refere à possibilidade de redução da criatividade e da inovação pelo receio de ser mal-avaliado ou, nas palavras de um professor, optando pelo caminho mais fácil.

Como toda pesquisa, este estudo também tem suas limitações: seu caráter exploratório e não conclusivo (as descobertas aqui apresentadas não podem ser aplicáveis a quaisquer situações); a própria pergunta de pesquisa (já que determina seu objetivo e lhe confere um foco); a escolha das perguntas feitas (diferentes perguntas poderiam revelar outras abordagens, enriquecendo as descobertas ou conduzindo-as para campos distintos); e restrições de tempo e custos (a decisão do número de entrevistados foi tomada também se levando em conta esses aspectos).

Pesquisas adicionais podem advir dos achados do presente estudo. Entender o ponto de vista dos alunos pode trazer novas reflexões e complementar este trabalho.

\section{REFERÊNCIAS}

ALBERS-MILLER, N. D.; STRAUGHAM, R. D.; PRENSHAW, P. J. Exploring innovative teaching among marketing educators: perceptions of innovative activities and existing reward and support programs. Journal of Marketing Education, Boulder, v. 23, n. 3, p. 249-259, 200 I.

ARMSTRONG, J. S. Are student ratings of instruction useful? American Psychologist, Washington, v. 53, n. 6, p. 1223-1224, I998.

BACELlAR, F. C. T.; AGUIAR, S.; CASTILHO, N. JR. Tipologia dos alunos de um curso de Pós-Graduação em Administração com base na escolha de disciplinas eletivas. In: ENCONTRO NACIONAL DA ASSOCIAÇÃO NACIONAL DOS PROGRAMAS DE PÓS-GRADUAÇÃO EM ADMINISTRAÇÃO, 27., 2003, Atibaia. Anais... Atibaia: ANPAD, 2003. CD-ROM.

CLARK III, I.; FLAHERTY, T.; MOTTNER, S. Student perceptions of educational technology tools. Journal of Marketing Education, Boulder, v. 23, n. 3, p. I69-I77, Dec. 200 I. CUNHA, M. I. de. O bom professor e a sua prática. Campinas: Papirus, I994.

DENZIN, N. K. Interpretive interactionism. Thousand Oaks: Sage, 200I.

DESAI, S.; DAMEWOOD, E.; JONES, R. Be a good teacher and be seen as a good teacher. Journal of Marketing Education, Boulder, v. 23, n. 2, p. I36-I44, Aug. 200 I.

EMERY, C.; KRAMER, T.; TIAN, R. Customers vs. products: adopting an effective approach to business students. Quality Assurance in Education, Bradford, v. 9, n. 2, p. IIO-II5, 200 I.

FERRELL, O. C. Improving marketing education in the I99०'s: a faculty retrospective and perspective view. Marketing Education Review, Columbia, v. 5, n. 3, p. I-6, I995.

FRANZ, R. S. Whatever you do, don't treat your students like customers! Journal of Management Education, Thousand Oaks, v. 22, n. I, p. 63-69, Feb. I998. 
GODOY, A. S. Ensino universitário: fatores influentes em sala de aula sob a ótica do aluno. In: WANDERLEY, L. E. W.; D’ANTOLA, A. (Orgs.). A prática docente na universidade. São Paulo: EPU, I992. p. 67-89.

GOODE, W. J.; HATT, P. K. Methods in social research. Nova York: McGraw Hill, I952.

GOULDING, C. Grounded theory: a practical guide for management, business and market researchers. London: Sage Publications, 2002.

IKEDA, A. A.; VELUDO-DE-OLIVEIRA, T. M.; MIYAZAKI, M. A disciplina de marketing na perspectiva discente: um estudo comparativo com estudantes de graduação e pós-graduação. In: CONGRESSO LATINO-AMERICANO DE ESTRATÉGIA, I7., 2004. Anais... Itapema: SLADE, 2004. KRUGLIANSKAS, I.; VASCONCELLOS, E. P. G. Avaliação de docentes na universidade: estudo de caso no departamento de administração da FEA/USP. In: SEMINÁRIO LATINO-AMERICANO DE GESTIÓN TECNOLÓGICA, 9., 2002, San José. Anais... San José: ALTEC, 2002. I CD-ROM. LOCKE, K. D. Grounded theory in management research. London: Sage Publications, $200 \mathrm{I}$. MASETTO, M. T. Competência pedagógica do professor universitário. São Paulo: Summus Editorial, 2003.

MECENAS, D. S. A avaliação de professores universitários: uma discussão crítica. In: XXXVII ASSEMBLÉIA DO CONSELHO LATINO-AMERICANO DE ESCOLAS DE ADMINISTRAÇÃO, 37. 2002, Porto Alegre. Anais... Porto Alegre: CLADEA, 2002.

MOREIRA, D. A. (Org.). Didática do ensino superior. São Paulo: Pioneira, I997.

OLIVEIRA, T. M. V. de. Valor em serviços educacionais: um estudo sobre o marketing educacional no contexto da teoria das cadeias meios-fim. 2003. Dissertação (Mestrado em Administração)Faculdade de Economia, Administração e Contabilidade da Universidade de São Paulo, São Paulo, 2003.

PIMENTA, S. G.; ANASTASIOU, L. G. C. Docência do ensino superior. São Paulo: Cortez, 2002. v. I. SCRABEC Jr., Q. A quality education is not customer driven. Journal of Education for Business, Washington, v. 75, n. 5, p. 298-300, May/Jun. 2000.

STRAUSS, A. Qualitative analysis for social scientists. New York: Cambridge University Press, I987, p. I9.

STRAUSS, A.; CORBIN, J. Basics of qualitative research. Techniques and procedures for developing grounded theory. Thousand Oaks: Sage Publications, I998.

TAYLOR, S. J.; BOGDAN, R. Introduction to qualitative research methods. New York: John Wiley \& Sons, I998.

ZABALZA, M. A. O ensino universitário: seu cenário e seus protagonistas. Porto Alegre: Artmed, 2002.

\section{TRAMITAÇÃO}

Recebido em 27/3/2007

Aprovado em 10/7/2008 